\title{
ON THE NATURE OF THE TOXIC SUBSTANCE FROM PNEUMOCOCCI.*
}

\author{
E. C. ROSENOW.
}

(From the Memorial Institute for Injectious Diseases, Chicago.)

The close relation between disintegration of bacteria in general and the production of soluble toxic substances, as I have shown, ${ }^{\mathrm{r}}$ might be interpreted as meaning that preformed endotoxin is liberated. The fact that the toxic substances obtained by autolysis of the various species are identical in their action speaks against this idea. I have shown that the toxic substances are absent at first, that they appear at a certain stage of autolysis, and then disappear; hence it would seem that they are produced during the disintegration of the bacteria. In the salt solution suspensions I have shown by means of the polariscope and formol titration that this appearance and disappearance of toxic substances are associated with proteolysis. That it is not a question of solution of toxic material which it may be assumed is contained as such within the pneumococcus is shown further in the following experiments, in which proteolysis was prevented for a time and in which the pneumococci were broken up mechanically by grinding them with sterile, washed cold sand and cold salt solution in a mortar. Care was exercised in this experiment to select a strain of pneumococcus not too virulent, because in those of exceptionally high virulence there are already present in 24 -hour cultures many pneumococci undergoing autolysis. After grinding to the point when only an occasional pneumococcus could be found, and suspending the triturated mass in cold $\mathrm{NaCl}$ solution for two hours, the suspension was centrifugated clear. Seven cubic centimeters were then injected at once into the jugular veins of two normal guinea-pigs, weighing 200 gms. No immediate symptoms developed; in three hours the animals seemed ill, and both were dead the next morning from pneumococcemia. Similar results were obtained in others injected after the suspension had been kept

* Received for publication July $\mathbf{1}_{3}, 1_{912 .}$

Iour. Infecl. Dis., 1912, 10, p. II3. 
at $37^{\circ} \mathrm{C}$. for one, three, and six hours. The two at the end of six hours showed mild symptoms in three minutes after the injection. Those injected at the end of 18 hours died from typical symptoms in three minutes, while those injected at the end of 48 hours showed no symptoms and remained permanently well. Formol titration showed a definite increase in amino-nitrogen. A second experiment gave the same results.

In the light of these experiments and the other facts, the conclusion seems warranted that the toxic material which produces the acute death from bronchial spasm is produced at least in large part during retrogressive changes and does not exist preformed within the pneumococci.

The delayed toxic effect of pneumococcus extracts is greatest when there is present the largest amount of the substance which provokes bronchial and other spasms. Animals which survive the immediate symptoms often die in 18 to 24 hours with extensive hemorrhages. It seems therefore that it concerns more than one toxic substance. Without further proof, however, we could not be sure that the late death might not be due in part at least to the early damage of the cells produced by the substance which causes acute death from bronchial spasms. Hemorrhages occur in both instances, although those following acute death from bronchial spasm are relatively slight and occur chiefly in the lungs and diaphragm. Those observed in other regions are what one might expect from acute asphyxia from any cause. I have tried by various methods to remove the toxic substance which kills the animal by producing bronchial spasm so that the effect of larger doses of the material which seems to be responsible for the late death could be studied. That the substance which kills by producing bronchial spasm is capable of rapidly attaching itself to the cells is indicated by its exceedingly rapid action. Hence various adsorbing substances have been tried and it has been found that animal charcoal, particularly blood charcoal, removes this substance rapidly from toxic extracts. Thus $0.1 \mathrm{gm}$. per Io c.c. of extracts is sufficient to remove all toxic material in one hour. An extract which kills in two to three minutes from typical symptoms causes no immediate symptoms after such treatment, the animal remaining permanently 
well. If, however, twice that dose of charcoal-treated autolysate is injected, the animal is apt to die in 18 to 24 hours but with no immediate symptoms referable to the respiratory tract. The following observation also has been made in connection with the effect of animal charcoal on pneumococcus autolysates: When the toxicity is high the removal of the toxic substance is associated with a reduction in the formol titration figure, whereas after treatment of autolysates which have been allowed to become nontoxic, reduction in the titration figure is less pronounced. The explanation of this fact is not clear but it might be suggested that the toxic substance has a great affinity for the charcoal and that it carries with it amino-acids and in that way lowers the titration figure. From observations made on amino-acids we know that the respiratory symptoms are not due to these substances. Similar results have been obtained with animal charcoal in case of toxic mixtures prepared with serum and in autolysates reactivated by the addition of serum.

Barium sulfate does not remove the toxic substance. Living and heat-killed, virulent pneumococci do not remove the toxic substance from the autolysates but render them more toxic. Living nonvirulent pneumococci and autolyzed virulent pneumococci on the other hand diminish the toxicity slightly.

In my previous papers it is shown that ether, while not essential, makes it easier to obtain the highly toxic effect of bacterial autolysates. It was suggested that ether killed the bacteria and thus intensified the reaction. The possibility of the substance being soluble in ether which thus serves to extract it from the disintegrating bacterial cell also suggests itself. This point has been studied, and it has been found that the substance which kills by bronchial spasm can be separated completely from toxic autolysates by ether extraction. The results in Table $\mathbf{I}$ are typically illustrative. It is seen that as the toxic autolysate or extract loses its acute toxic effect by the extraction, and that the ether soluble residue, suspended in an equivalent amount of $\mathrm{NaCl}$ solution, becomes toxic in direct proportion. The amount of amino-nitrogen lost in the broth is equal to that found in the ether extract. This fact suggests strongly that the toxic substance contains nitrogen, and because 
it is available in the formol titration, it is probably an amin. In order to remove all this toxic substance it is necessary to use large quantities of ether (three to six times the amount of extract) and to shake thoroughly for ro to 20 minutes in each extraction, the substance being soluble in ether with some difficulty. The fact that ether fails to remove this toxic substance when partially autolyzed pneumococci have not been removed from the extract shows that they have a certain affinity for the toxic substance. This undoubtedly explains why it is more difficult to obtain free in the $\mathrm{NaCl}$ solution a sufficient amount of toxic material in the absence of ether because digestion within the pneumococci may go beyond the toxic stage before the product is free in the $\mathrm{NaCl}$ solution.

TABLE I.

Extraction of Acutely Toxic Substance witr Ether.

\begin{tabular}{|c|c|}
\hline $\begin{array}{l}\text { Mixtures } \\
\text { (Extract } 284 \text { was prepared from two strains of highly virulent } \\
\text { pneumococci }[617 \text { and } 618] \text {, grown in meat broth for } 24 \text { hours, washed } \\
\text { once, suspended in } \mathrm{NaCl} \text { solution in the usual way, and placed at } \\
37^{\circ} \mathrm{C} \text {. for } 48 \text { hours.) }\end{array}$ & $\begin{array}{l}\text { Symptoms on jugular injection } \\
\text { in (duplicate) guinea-pigs }\end{array}$ \\
\hline 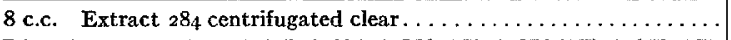 & Death in 4 minutes \\
\hline 8 c.c. Extract 284 with pneumococci not removed . . . . . . . . & Death in $3^{\frac{1}{2}}$ minutes \\
\hline $\begin{array}{l}8 \text { c.c. Extract } 284 \text { clear and after } 3 \text { extractions in } 3 \text { times the } \\
\text { amount of ether } \ldots \ldots \ldots \ldots \ldots \ldots \ldots \ldots \ldots \ldots \ldots \ldots \ldots \ldots \ldots \ldots \ldots\end{array}$ & $\begin{array}{l}\text { No immediate symptoms, death } \\
\text { with hemorrhages in } 8 \text { hours }\end{array}$ \\
\hline $\begin{array}{l}8 \text { c.c. Extract } 284, \text { pneumococci not removed, treated with ether as } \\
\text { above. } \ldots \ldots \ldots \ldots \ldots \ldots \ldots \ldots \ldots \ldots \ldots \ldots \ldots \ldots \ldots \ldots \ldots\end{array}$ & Death in 4 minutes \\
\hline $\begin{array}{l}\text { Ether soluble substance from } 8 \text { c.c. of clear extract suspended in } 8 \text { c.c. } \\
\text { of } \mathrm{NaCl} \text { solution } \ldots \ldots \ldots \ldots \ldots \ldots \ldots \ldots \ldots \ldots \ldots \ldots \ldots \ldots \ldots \ldots\end{array}$ & $\begin{array}{l}\text { Death in a minutes from typical } \\
\text { symptoms, blood very dark }\end{array}$ \\
\hline 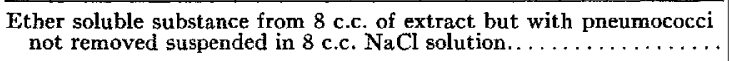 & $\begin{array}{l}\text { Slight symptoms, severe scratch- } \\
\text { ing, irritability, etc. }\end{array}$ \\
\hline
\end{tabular}

As soon as it was found that the acutely toxic substance was soluble in ether (Mallenkrodt's anesthetic ether was used) an attempt was made to extract it from highly virulent and unautolyzed pneumococci when suspended in $\mathrm{NaCl}$ solution, and when dried, but without success. When toxic pneumococcus autolysates are evaporated to dryness at room temperature, the residue ground up in a mortar with sand, and then extracted with ether, only a small amount of highly toxic substance is found in the ether residue. It is impossible to say whether the toxic substance is more soluble in 
the "watery" ether or destroyed during evaporation. It has also been extracted with ether from toxic autolysates of diphtheria bacilli as well as from extracts of pneumococci made toxic with immune serum and normal serum, with normal serum alone, and with leukocytes, and also from the clear broth culture filtrates of pneumococci. Moreover, by shaking ordinary peptone broth with ether and to a lesser degree dry powdered Witte peptone, an acutely toxic substance which produces similar symptoms is obtained.

Quantitative studies on the action of clear toxic autolysates and the ether soluble substance suspended in equivalent amounts of $\mathrm{NaCl}$ solution show that the latter are even more toxic than the former. The symptoms begin earlier, the respiratory efforts are not so violent, dose for dose, because the animal is overwhelmed too rapidly. If approximately three-fourths of the ether soluble substance of a measured toxic dose of the extract is injected, the spasms may be as pronounced as when the extract itself is injected. When the extracts fail to produce symptoms, then extraction with ether fails to remove any toxic material. Animal charcoal removes the toxic substance from $\mathrm{NaCl}$ solution suspensions of the ether soluble residue. Animal charcoal, which has taken up the toxic substance, gives up only a part of this substance when shaken with ether just as ether fails to remove in appreciable amounts the toxic substance from pneumococcus suspensions.

In Table 2 is shown the effect of blood charcoal and ether on the formol titration and toxicity of pneumococcus broth culture filtrates. There was used $0.2 \mathrm{gm}$. of the charcoal per Io c.c. of the clear culture fluid. It was allowed to act for one hour at $37^{\circ} \mathrm{C}$. The extractions with ether were repeated three times in the proportion of two parts of ether to one part of broth. There was observed here as in the autolysates a reduction in formol titration and toxicity.

When clear toxic pneumococcus autolysates are heated to $60^{\circ} \mathrm{C}$. from five to 20 minutes the toxicity for guinea-pigs disappears. When, however, suspensions of pneumococci have become highly toxic after having been kept at $37^{\circ} \mathrm{C}$. for 24 to $4^{8}$ hours and there are present a fair number of well preserved pneumococci the toxicity does not disappear nearly as easily.

Study of this peculiar result shows that if the heat is brought 
up to $60^{\circ} \mathrm{C}$. very gradually the toxicity might entirely disappear in from one to three hours, but if the suspension was plunged into boiling water the toxicity would frequently remain even after boiling for ro minutes. This heated suspension would now remain toxic for a long time when kept on ice.

TABLE 2 .

The Effect of Brood Charconl and Ether on the Toxicity and Formol Titration of Pnetumococcts Broth Culture Filtrates.

\begin{tabular}{|c|c|c|}
\hline Mixtures & $\begin{array}{l}\text { Formol } \\
\text { Titration }\end{array}$ & $\begin{array}{l}\text { Symptoms in (duplicate) } \\
\text { guinea-pigs following injec- } \\
\text { tion of } 4.5 \text { c.c. intravenously }\end{array}$ \\
\hline Meat broth culture pneumococcus $6224 \ldots \ldots \ldots \ldots \ldots$ & $\begin{array}{l}2 . \pi \\
4.2\end{array}$ & $\begin{array}{l}\text { Nearly dead in } 3 \text { minutes, dead } \\
\text { in } 20 \text { minutes }\end{array}$ \\
\hline Same after treatment with animal charcoal. ....... & $\begin{array}{l}\mathrm{x} .6 \\
3 \cdot 3\end{array}$ & Slight symptoms in ro minutes \\
\hline Same after ether extraction..$\ldots \ldots \ldots \ldots \ldots \ldots \ldots \ldots$ & $\begin{array}{l}2.1 \\
3.9\end{array}$ & Definite symptoms \\
\hline Meat broth control* $\ldots \ldots \ldots \ldots \ldots \ldots \ldots \ldots \ldots \ldots$ & .65 & Definite symptoms \\
\hline
\end{tabular}

*The ether extract from I6 c.c. of the broth culture fluid produced marked symptoms, while that from the broth treated in exactly the same way gave no definite symptoms.

An analogous observation has been made with pneumococcus broth culture fluids. When the pneumococci are removed heating reduces the toxicity markedly, whereas, when the organisms are allowed to remain, heating reduces their toxicity only slightly or not at all. Similar results have been obtained with extracts of pneumonic lungs. It seems, therefore, that the rapid disappearance of the toxic property of the clear extracts is due to ferment action. The toxic substance is converted rapidly into nontoxic material, but where there is present a supply of material which has not yet reached the toxic stage, new toxic material is made until the ferment itself is destroyed and heating no longer destroys the toxic substance. It seems, therefore, that the toxic substance is really thermostable and not thermolabile as one would be led to believe from the effect of heat on the clear extracts.

The effect of acids and alkalies on the toxic substance has also been studied. The reaction of the autolysate is practically neutral. If clear toxic pneumococcus autolysates are made 2 per cent acid with hydrochloric acid and this at once neutralized with sodium 
carbonate or sodium hydrate, it is found that the substance which provokes bronchial spasm has entirely disappeared. Lower concentrations of acid require a longer time until all the toxic substance disappears. If other portions are alkalinized to the same degree and neutralized with hydrochloric acid, the toxic action is reduced to a lesser degree. Similar but less striking results have been obtained with pneumococcus broth culture filtrates. It would therefore seem that the toxic substance is an amino-base and might very well be $\mathbf{B}$. imidoazolylethylamine which Dale and Laidlow ${ }^{\mathrm{T}}$ have isolated from Witte peptone and which they believe to be the substance which provokes bronchial spasm in guinea-pigs.

By means of the ether I am thus able to separate, in more or less pure form, the toxic substance from the other protein constituents of the pneumococcus autolysates.

The question whether intoxication and immunization during infections are due to the same cause, or whether substances are formed which not only intoxicate without at the same time calling forth antibody formation, but even interfere with antibody production, is still unsettled. I have shown that intravenous injections of extracts of pneumococci before, during, and especially after the toxic stage protect guinea-pigs against subsequent injections of toxic autolysates. This is specific for pneumococci. It has now been found that nonfatal doses of the toxic, ether soluble material does not protect against toxic autolysate or against toxic ether soluble material. The autolysates on the other hand, both before and after ether extraction, protect against the toxic ether soluble material and toxic autolysates.

CONCLUSIONS.

The toxic substance obtainable from pneumococci has been found to be soluble in ether. It is formed chiefly during retrogressive changes in pneumococci. Heating the clear toxic autolysate to $60^{\circ} \mathrm{C}$ for 20 minutes destroys the toxicity, while toxic pneumococcus suspensions remain toxic even after boiling Hydrochloric acid in weak solution destroys the toxicity of pneumococcus autolysates. The toxic substance is adsorbed by blood charcoal

Jour. of Physiol., 1910, 4t, p. 318. 
from which it can again be obtained by shaking with ether. Autolyzed virulent pneumococci and nonvirulent pneumococci diminish the toxicity slightly while unautolyzed virulent pneumococci increase it. The toxic substance is probably a base which contains amino groups of nitrogen.

Indications have been obtained showing that during pneumococcus infections toxic substances are produced which do not call forth any immunizing response. 